\title{
Levels, Trends and Differentials of Natural Births and Cesarean Births in Chittagong, Bangladesh
}

\author{
Mohammad Manjur Alam* \\ Dept. of Computer Science and Engineering, International Islamic University Chittagong (IIUC), \\ Chittagong-4318, Bangladesh. \\ Dr. Razaul karim \\ Department of Medicine, Chattagram International Medical College and Hospital \\ Dr. Md. Musa Khan \\ Department of Business Administration, International Islamic University Chittagong (IIUC) \\ Shahidul Islam Khan \\ Dept. of Computer Science and Engineering, International Islamic University Chittagong (IIUC) \\ Md Arif Billah \\ Department of Quranic Sciences and Islamic Studies, International Islamic University Chittagong (IIUC)
}

\begin{abstract}
The type of last delivery of a mother is vital as it has a significant impact on mother and child health. The percentage of cesarean or C-section births has increased alarmingly in Bangladesh. Births through C-section have complicated and unsafe when compared to normal deliveries although sometimes it is unavoidable. This study assessed the current scenario of cesarean births and natural births in the region of Chittagong, Bangladesh. A total of 569 mothers' data have been collected by schedule methods from the different areas of Chittagong from October to December 2018. Descriptive Statistics, chi-square $\left(\chi^{2}\right)$ test and binary logistic regression have been used to determine the performance of delivery status in Chittagong. Chi-square $\left(\chi^{2}\right)$ test reveals that a number of factors are significantly associated with the performance of the delivery type. Binary logistic regression shows that only two factors 'Delivery place' and 'Cost of last delivery' have a significant effect on delivery status in Chittagong. Keywords: Delivery type; C-section; Natural birth; Chittagong; Bangladesh
\end{abstract}

DOI: $10.7176 / \mathrm{JHMN} / 69-04$

Publication date: December $31^{\text {st }} 2019$

\section{Introduction}

A mother can deliver her baby either naturally or by surgical operation (C-section). Both delivery procedures have some merits and demerits. Natural childbirth is a birth that happens with the help of a doctor or a skilled attended in a hospital, a midwife attended at home, or without any aid. It has natural progress and many other advantages other than C-section. Except for some crucial situations where cesarean birth becomes the preference for childbirth or without maternal death, natural or vaginal birth is measured as the best and safest option. The prevalence of $\mathrm{C}$ section among 137 countries, in which 69 countries were more than $15 \%$ and 54 countries less than 10\% (Gibbons et al., 2012). The C-section rate varies from country to country and their urban and rural areas, socio-economic condition and different public and private services (Strom S.,2013). Both the developed and developing countries have become concerned about C-section (Feng, Akintayo et al., 2014, Adam I., 2014). Research has found that a decline in the $\mathrm{C}$-section is associated with little risk of maternal morbidity and deaths. Various common factors have been recognized which are interrelated to normal and cesarean delivery, but a good number of the essential factors were not integrated into the previous study. Some common indicators which are related to cesarean delivery such as maternal age at birth (Parrish KM et al., 1994), Parity (Mossialos et al., 2005), the weight of birth (Onwude JL,2005), socioeconomic status (Skalkidis,1996) etc. Age at first marriage is also a significant cause of cesarean birth rates in developing countries (Rahman M et al., 2012). Huda et al. (2012) also found that among women having ten years plus schooling $\mathrm{C}$-section was more common without any pregnancy-related problem. With the decrease in women's level of education, the likelihood of C-section decreased. Jisun and Kabir (2014) found that the vaginal delivery of uneducated women is about $85 \%$ and cesarean delivery has a secondary level of education is about $55 \%$.

In Bangladesh, surgical operations in case of delivery are increasing day by day. At this moment the natural delivery system is one of the critical and challenging issues of our country. According to BDHS 2014, the actual rate of C-section births in Bangladesh was just 4\% in 2004. It rises from 4.0\% to 23\% between 2004 and 2014. The number of $\mathrm{C}$-section deliveries in Bangladesh has increased to five-fold in this duration. The $\mathrm{C}$-section rate of the private hospitals in Bangladesh is $73 \%$ (Neuman M, Alcock G, Azad K, et al.2014). The C-section rate in 
urban areas is $56.8 \%$, and it is also higher in educated women (51.2\%). According to Save the Children report (FE Report: August 15, 2017) the unnecessary cesarean births in Bangladesh are $70 \%$ which annually costs $\$ 315$. However, in Bangladesh, researchers' asses that more than $80 \%$ of the deliveries in private hospitals are cesarean births (Source: Daily Star- December 28, 2017). WHO suggested that C-section births in a country should not be more than $15 \%$. So it is one of the biggest challenges in Bangladesh's to stop the unnecessary cesarean delivery in Bangladesh. In addition, if a mother desires to have more children, C-section creates many of the risks of complexity. Although some women believe C-section is more flexible than natural birth. They think that it is a modern method that is incorporating technology using (Lowdon\& Derrick, 2002). Considering these realities, this study was designed on the current scenario of natural births and cesarean births in Chittagong, Bangladesh. However, little research has been done on the above issue in Bangladesh, but any research has not been yet done in the second-largest city in Chittagong, Bangladesh. Therefore, an attempt has been made to measure the levels, trends and differentials on the current scenario of natural births and cesarean sections based on the primary data in the region of Chittagong, Bangladesh.

\section{Materials and Methods Study Area}

The region of Chittagong is situated in the south-eastern part of Bangladesh. It is the second-largest city in Bangladesh with a total area of $33,771.18 \mathrm{~km}^{2}(13,039.13 \mathrm{sq} \mathrm{mi})$ and a population at the 2011 census of $28,423,019$. It has eleven districts (zilas) and 99 sub-districts (Upazilas).

\section{Source of data}

To meet the objectives of this study, primary data have been collected from different areas in the Chittagong division. Women aged 15 to 49 who had at least one birth during their reproductive lifespan have been selected randomly and a personal interview has been taken using the close and open-ended questionnaires.A total of 569 mothers' data have been collected from the different areas of Chittagong, Bangladesh during the period of October to December 2018. Among 569 mothers, 369 are cesarean, and the remaining 200 are non-cesarean.

\section{Variables}

The survey has considered the socio-demographic, maternal and others relevant factors that influence the assessment of cesarean and normal delivery process while the dichotomous dependent variable has been considered as the type of delivery process that is $\mathrm{C}$-section or normal delivery coded as $0=$ "Normal delivery" and $1=$ "C-section".

\section{Statistical Analysis}

Descriptive statistics, bivariate analysis of Chi-square $\left(\chi^{2}\right)$ and binary logistic regression technique have been used to find out the real scenario of normal and cesarean delivery and its level, trends and differentials. Chi-square $\left(\chi^{2}\right)$ test was performing to compare the distributions of normal delivery and C-section under different factors.Binary logistic regression was applied to determine whether the independent variables can predict the dependent variable delivery type. Multicollinearity was checked before logistic regression. The data have been analyzed using the Statistical Packages for Social Sciences (SPSS) software for windows (version 24.0).

\section{Results \\ Descriptive analysis}

Table 1 shows the percentage distribution of socio-demographic and other relevant characteristics of study women. Most of the mothers' age lies between the age group 26-35 years with a mean and standard deviation of 31.04 \pm 6.71 years. Urban respondents are 2.5 fold higher than rural respondents. The rate of Higher Secondary or above women $(59.4 \%)$ is larger than illiterate $(4.9 \%)$ and primary $(1.2 \%)$ educated women respectively. Table 1 also illustrates that $80 \%$ of respondents' occupation is in homemakers. With regard to respondents' age at first marriage most of the respondents' ages lie between 19-24 years. The average age at first marriage and first births are 20.63 \pm 3.5 and $22.67 \pm 3.66$ years respectively. Of the total births, $80.7 \%$ took place from 2010 to March 2018 . The percentage of C-section delivery is higher among the women who received ANC and ultrasonography services at least one time during their last pregnancy period. The place of delivery is one of the most important factors that affect the delivery outcome. Among the total deliveries, the institutional birth is $89 \%$, and normal birth in a home is $11 \%$. In Chittagong, the rate of Cesarean birth in a private hospital is $81.1 \%$, and a public hospital is $7.9 \%$. The average cost of the last delivery is TK. 22,985 but in case of caesarian birth it is Tk. 31,582 and natural childbirth is TK. 6998. Earning the profit goal of private hospitals might be one of the important reasons for these differences. The similar finding shows that the average cost for both deliveries is very high in a private hospital. Khan et al., (2012) observed that the charges for C-section are usually at least double compared to normal delivery. Regarding wealth index, only $1.9 \%$ is low socio-economic classes, $79.3 \%$ are from middle classes, and $36.4 \%$ are from higher 
class family.

There are many causes to suggest a cesarean delivery. Mothers' health crisis directly or indirectly affect the having natural births. Studies have shown that the most common reasons of C-section have been found in mothers' physical problem (43.1\%) which includes heart disease, high blood pressure, or gestational diabetes, infection, excessive bleeding, organ damage, injuries to the bladder or any other health crisis. Babies' unusual position was the second important cause (22.5\%). Other essential causes of women who had to undergo cesarean surgeries were repeated C-section (11.1\%), Babies' abnormal weight (3.3\%), Placenta previa (1.6\%) and expected date crossing $(6.5 \%)$. It is interesting that $11.9 \%$ of mothers do not know their specific causes or it is not clear whether they are influenced by the doctor, institutional, individual or family members. $57.2 \%$ of women reflect that there is no physical problem after the surgical operation while $42.8 \%$ suffer many physical problems after caesarian delivery. The person who influences in cesarean deliveries have found that $85.4 \%$ recommend the doctor, $2.4 \%$ support the institutional, $12.2 \%$ family members and others. Therefore advice from the doctor has been found to play a significant role in case of cesarean deliveries (Aminu et al., 2014).

Table 1: Percentage distributions of respondents according to the background characteristics

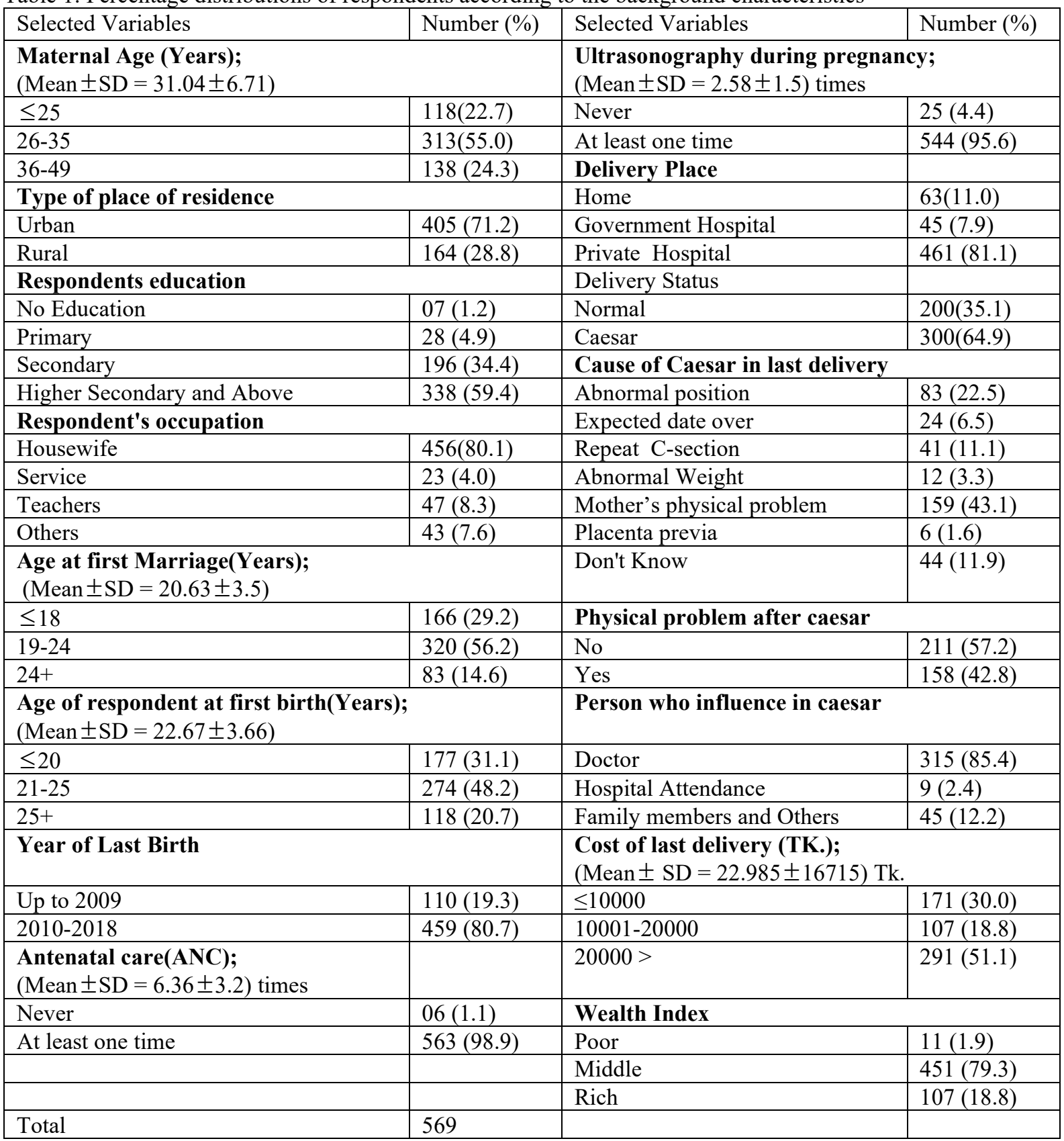

Differentials of Delivery Type in Chittagong, Bangladesh

Bivariate analysis has been explored to underlying the significant association between the dependent variables 
types of deliveries (Caesar /Normal) and the explanatory variables. The dependent variable is coded as 1 for mothers who had cesarean delivery and 0 for those who had a normal delivery. Out of 12 explanatory variables nine independent variables have been found statistically significantly associated with delivery type. For examining the bivariate relationship chi-square test is used and values of $\chi^{2}$ test statistics along with $p$ values are in Table 2.It is seen that the independent variables 'Maternal Age', 'Respondents Year of Last Birth', 'Ultrasonography during pregnancy', 'Delivery Place', 'Cost of last delivery' are found to be highly significant. 'Age of respondent at first birth', is significant at 1\% level, and 'Respondents education', 'Wealth Index', has a significant effect on types of deliveries at 5\% level. The remaining independent variables are not found significant. Mothers' age plays an important role in the performance of the delivery type. Among all the age categories cesarean deliveries is higher than normal delivery. Table 2 reflects that the number of the natural delivery in urban areas $(32.8 \%)$ is less than that in rural areas $(40.9 \%)$, where as the number of C-section delivery in urban areas $(67.2 \%)$ was higher than that in rural areas $(59.1 \%)$.

Higher educated women had a cesarean section much more than illiterate, primary or secondary educated women. Among the highly educated women, the rate was $69.5 \%$. Among all the categories of respondents' education cesarean deliveries is higher than normal delivery. In case of respondents' age at first births, C-section deliveries were found to be less frequent in the age group 14-20 years (58.8\%) as compared to other age groups. Data collected from 1991 to 2009 reflect that natural birth $(52.7 \%)$ was higher than cesarean delivery (47.3) but after 2009 cesarean delivery $(69.1 \%)$ was higher than natural delivery $(30.9 \%)$. This performs the real scenario of increasing $\mathrm{C}$-section rate in recent time. The highest cesarean rate is also observed women who have received at least a one-time ultrasonography during pregnancy period. It was interesting as the time of ultrasonography increasing the probable rate of normal delivery was also decreasing. The cesarean section rate in public hospitals is $7.3 \%(45)$, while in private hospitals the rate is $81.1 \%(461)$. The study incurred that in case of normal delivery $(79.5 \%)$ mothers' cost is up to TK. 10000 . On the contrary, it is showed that in case of Cesarean delivery $77 \%$ mothers' cost was above 20 thousand Taka. This is the probable reason for high cesarean deliveries in private hospitals. Mothers from low socioeconomic class had a higher rate in normal delivery (63.6\%) when compared to Cesarean delivery $(36.4 \%)$. While, the higher rate of cesarean delivery $(72 \%)$ was pragmatic among mothers of higher socioeconomic groups.

Table 2: Test of independence between delivery type and background characteristics of mothers

\begin{tabular}{|c|c|c|c|c|c|}
\hline \multirow{2}{*}{ Variables } & \multirow{2}{*}{ Category } & \multicolumn{2}{|l|}{ Delivery Type } & \multirow[t]{2}{*}{$\chi^{2}$-Value } & \multirow[t]{2}{*}{ P-Value } \\
\hline & & Normal $(35 \%)$ & Caesar $(65 \%)$ & & \\
\hline \multirow{3}{*}{ Maternal Age (Years) } & $\leq 25$ & $47(39.8 \%)$ & $71(60.2 \%)$ & \multirow{3}{*}{18.289} & \multirow{3}{*}{0.000} \\
\hline & $26-35$ & $87(27.8 \%)$ & $226(72.2 \%)$ & & \\
\hline & $36-49$ & $66(47.8 \%)$ & $72(52.2 \%)$ & & \\
\hline \multirow{2}{*}{$\begin{array}{l}\text { Type of place of } \\
\text { residence }\end{array}$} & Urban & $133(32.8 \%)$ & $272(67.2 \%)$ & \multirow{2}{*}{3.289} & \multirow{2}{*}{0.070} \\
\hline & Rural & $67(40.9 \%)$ & $97(59.1 \%)$ & & \\
\hline \multirow{4}{*}{ Respondents education } & Illiterate & $3(42.9 \%)$ & $4(57.1 \%)$ & \multirow{4}{*}{8.268} & \multirow{4}{*}{0.041} \\
\hline & Primary & $13(46.4 \%)$ & $15(53.6 \%)$ & & \\
\hline & Secondary & $81(41.3 \%)$ & $115(58.7 \%)$ & & \\
\hline & $\begin{array}{l}\text { Above } \\
\text { Secondary }\end{array}$ & $103(30.5 \%)$ & $235(69.5 \%)$ & & \\
\hline \multirow{4}{*}{$\begin{array}{l}\text { Respondent's } \\
\text { occupation }\end{array}$} & Housewife & $169(37.1 \%)$ & $287(62.9 \%)$ & \multirow{4}{*}{4.531} & \multirow{4}{*}{0.210} \\
\hline & Service & $6(26.1 \%)$ & $17(73.9 \%)$ & & \\
\hline & Teachers & $11(23.4 \%)$ & $36(76.6 \%)$ & & \\
\hline & Others & $14(32.6 \%)$ & $29(67.4 \%)$ & & \\
\hline \multirow{3}{*}{$\begin{array}{ll}\text { Age } \quad \text { at } & \text { first } \\
\text { Marriage(Years) } & \end{array}$} & $\leq 18$ & $62(37.3 \%)$ & $104(62.7 \%)$ & \multirow{3}{*}{1.799} & \multirow{3}{*}{0.407} \\
\hline & $19-24$ & $114(35.6 \%)$ & $206(64.4 \%)$ & & \\
\hline & $24+$ & $24(28.9 \%)$ & $59(71.1 \%)$ & & \\
\hline \multirow{3}{*}{$\begin{array}{l}\text { Age of respondent at } \\
\text { first birth(Years) }\end{array}$} & $14-20$ & $73(41.2 \%)$ & $104(58.8 \%)$ & \multirow{3}{*}{8.716} & \multirow{3}{*}{0.013} \\
\hline & $21-25$ & $98(35.8 \%)$ & $176(64.2 \%)$ & & \\
\hline & $25+$ & $29(24.6 \%)$ & $89(75.4 \%)$ & & \\
\hline \multirow{3}{*}{$\begin{array}{l}\text { Respondents Year of } \\
\text { Last Birth }\end{array}$} & Up to 2009 & $58(52.7 \%)$ & $52(47.3 \%)$ & \multirow{3}{*}{18.484} & \multirow{3}{*}{0.000} \\
\hline & $2010-2018$ & $142(30.9 \%)$ & $317(69.1 \%)$ & & \\
\hline & Yes & $86(39.3 \%)$ & $133(60.7 \%)$ & & \\
\hline \multirow{2}{*}{$\begin{array}{l}\text { Visiting } \\
\text { Chamber }\end{array}$} & Never & $4(66.7 \%)$ & $2(33.3 \%)$ & \multirow[b]{2}{*}{2.643} & \multirow[b]{2}{*}{0.104} \\
\hline & $\begin{array}{l}\text { At least one } \\
\text { time }\end{array}$ & $196(34.8 \%)$ & $367(65.2 \%)$ & & \\
\hline Ultrasonography & Never & $19(76.0 \%)$ & $6(24.0 \%)$ & 19.143 & 0.000 \\
\hline
\end{tabular}




\begin{tabular}{|c|c|c|c|c|c|}
\hline During Pregnancy & $\begin{array}{l}\text { At least one } \\
\text { time }\end{array}$ & $181(33.3 \%)$ & $363(66.7 \%)$ & & \\
\hline \multirow{3}{*}{ Delivery Place } & Home & $62(100.0 \%)$ & $0(0.0 \%)$ & \multirow{3}{*}{128.407} & \multirow{3}{*}{0.000} \\
\hline & $\begin{array}{l}\text { Government } \\
\text { Hospital }\end{array}$ & $12(26.1 \%)$ & $34(73.9 \%)$ & & \\
\hline & Private hospital & $126(27.3 \%)$ & $335(72.7 \%)$ & & \\
\hline \multirow{3}{*}{$\begin{array}{l}\text { Cost of } \\
\text { delivery(TK.) }\end{array}$} & $\leq 10000$ & $159(79.5 \%)$ & $12(3.3 \%)$ & \multirow{3}{*}{375.199} & \multirow{3}{*}{0.000} \\
\hline & $10001-20000$ & $34(17.0 \%)$ & $73(19.8 \%)$ & & \\
\hline & $20000>$ & $7(3.5 \%)$ & $284(77.0 \%)$ & & \\
\hline \multirow{3}{*}{ Wealth Index } & Poor & $7(63.6 \%)$ & $4(36.4 \%)$ & \multirow{3}{*}{6.485} & \multirow{3}{*}{0.039} \\
\hline & Middle & $163(36.1 \%)$ & $288(63.9 \%)$ & & \\
\hline & Rich & $30(28.0 \%)$ & $77(72.0 \%)$ & & \\
\hline Chittagong & & $200(35.1 \%)$ & $369(64.9 \%)$ & & \\
\hline
\end{tabular}

Trends in normal delivery and cesarean section

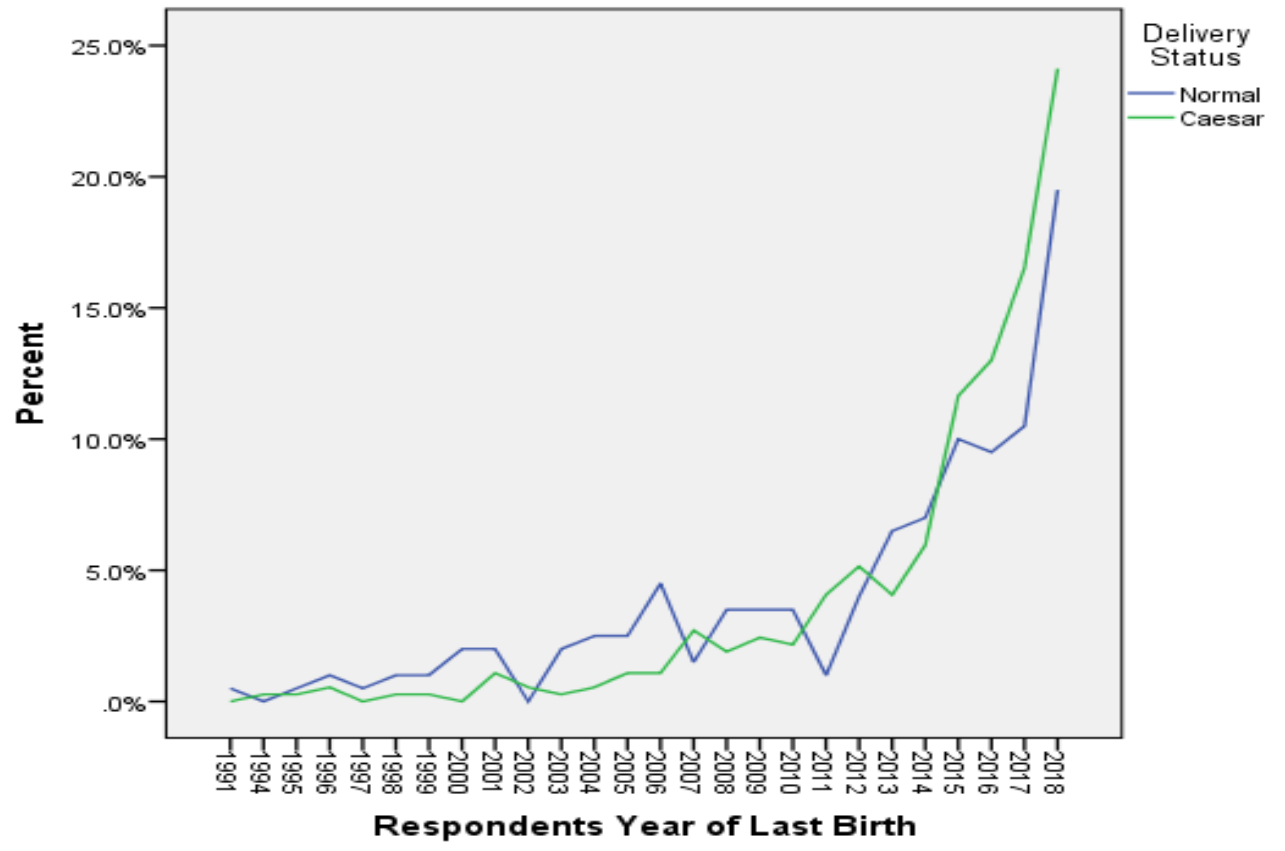

Trend in normal and cesarean deliveries by region in Chittagong. Bangladesh (1991-2018)

Figure 1. Trend line of comparison between Normal and Cesarean Births in Chittagong, Bangladesh

Figure 1 shows the trends in normal and cesarean rate from 1991 to 2018 in Chittagong, Bangladesh. The horizontal axis represents the years from 1991 to 2018, while the perpendicular axis represents mode of delivery rates (percent). The trend of each line indicates that, with the year changes, the status of last delivery is also changes. From 1991 to 2006 the natural birth was higher than cesarean birth in Chittagong except the year 1994 and 2002. But the trend of natural delivery and C-section rate were fluctuating from 2007 to 2011. In 2010 and 2011, the Csection rates were higher than natural delivery rates. However, in 2013, the normal delivery rate was lower than the C-section delivery. From 2014 to 2018 a significant rising trend in the rate of C-section has been observed in Chittagong. The C-section rate of Chittagong region in 2007 was $1.90 \%$ to $4.07 \%$ in 2010 and to $24.12 \%$ in 2018 . Therefore the $\mathrm{C}$-section rate in Chittagong was slightly higher than the national average (23\%) as per the BDHS2014, and it is well above WHO recommendations of the ideal rate for cesarean delivery.

\section{Determinants of $\mathbf{C}$-section (Logistic regression analysis)}

In addition to studying the test of independence of cesarean deliveries with background characteristics of the women, binary logistic regression is also employed. The purpose of this study is to examine the specific risk for the determinant of delivery status in Bangladesh. This risk factor is indispensable to reduce the cesarean section rate in Chittagong region. The dependent variable delivery by cesarean section is dichotomous in nature $(0=$ No, $1=$ Yes). Nine explanatory variables have been considered in this study, which are found to have a significant effect with delivery type in bivariate analysis. Among these variables, only two variables, 'Delivery place' and 'Cost of last delivery' have a significant effect on delivery type. The odds along with $95 \%$ confidence intervals are 
also considered. The logistic regression analysis shows that only two important factors are responsible for the determinants of $\mathrm{C}$-section delivery in Chittagong. All other variables are not significant with delivery type. An odd between mother's age and delivery status for women aged 26 to 35 years was 2.262 times higher compared to the reference age group ( $\leq 25$ years), and this age group is statistically significant. Women who had at least onetime check-up by Ultrasonography are 2.087 times more likely to have cesarean deliveries who have not received any ultrasonography during pregnancy, and it is not found as a significant risk factor for influencing C-section deliveries. The analysis shows that $\mathrm{C}$-section deliveries are more likely to occur among the births in private hospitals compared to natural birth in home and it is the most important significant factor in analyzing the delivery process. Costs of last delivery have been found as another critical, significant risk factor for determining C-section deliveries. Women whose last delivery cost is Tk. (10001-20000) and more than TK. 20000 have 33.48 and 912.51 times more likely to be C-section than women whose last delivery cost up to Tk. 10000 . Although wealth index is the most important factor for determining the delivery status but it is not statistically significant. Women from middle-class family have 1.175 times more likely to be C-section than women from low-income family and Odds of women highest wealth quintile is 1.471 times higher compared to low economic class.

Table 3: Logistic regression analysis of types of delivery and significant background characteristics of the respondents

\begin{tabular}{|c|c|c|c|c|c|c|c|}
\hline \multirow[t]{2}{*}{ Variables } & \multirow[t]{2}{*}{ Category } & \multirow[t]{2}{*}{ B } & \multirow[t]{2}{*}{ S.E. } & \multirow[t]{2}{*}{ Sig. } & \multirow[t]{2}{*}{$\operatorname{Exp}(B)$} & \multicolumn{2}{|l|}{$\begin{array}{l}95 \% \\
\mathrm{EXP}(\mathrm{B})\end{array}$} \\
\hline & & & & & & Lower & Upper \\
\hline \multirow{3}{*}{ Age of respondent } & $(\leq 25)$ & & & .223 & & & \\
\hline & $26-35$ & .800 & .468 & .087 & 2.226 & .890 & 5.570 \\
\hline & $36-49$ & .885 & .736 & .229 & 2.422 & .573 & 10.241 \\
\hline \multirow{2}{*}{ Type of place of residence } & (Urban) & & & & & & \\
\hline & Rural & -.483 & .407 & .234 & 617 & .278 & 1.368 \\
\hline \multirow{4}{*}{ Respondents education } & (Illiterate) & & & .887 & & & \\
\hline & Primary & -.056 & 1.607 & .972 & .946 & .041 & 22.039 \\
\hline & Secondary & -.861 & 1.586 & .587 & .423 & .019 & 9.464 \\
\hline & Above Secondary & -.850 & 1.581 & .591 & 428 & .019 & 9.480 \\
\hline \multirow{3}{*}{$\begin{array}{l}\text { Age of respondent at } \\
\text { birth(Years) }\end{array}$} & $(\leq 20)$ & & & .440 & & & \\
\hline & $21-25$ & -.247 & .414 & .551 & .781 & .347 & 1.759 \\
\hline & $25+$ & .351 & .572 & .540 & 1.421 & .463 & 4.360 \\
\hline \multirow{2}{*}{ Respondents Year of Last Birth } & (Up to 2009) & & & & & & \\
\hline & $2010-2018$ & -.607 & .638 & .341 & .545 & .156 & 1.903 \\
\hline \multicolumn{8}{|c|}{ Ultrasonography $\quad$ During(Never $)$} \\
\hline Pregnancy & At least one time & .736 & 1.025 & .473 & 2.087 & .280 & 15.570 \\
\hline \multirow{3}{*}{ Delivery Place } & (Home) & & & .002 & & & \\
\hline & $\begin{array}{l}\text { Government } \\
\text { Hospital }\end{array}$ & 20.515 & 4955.103 & .997 & 811700368.7 & 7.000 & \\
\hline & Private hospital & 18.514 & 4955.103 & .997 & 109830178.0 & .000 & \\
\hline \multirow{3}{*}{ Cost of last delivery(TK.) } & $(\leq 10000)$ & & & .000 & & & \\
\hline & $10001-20000$ & 3.511 & .491 & .000 & 33.476 & 12.796 & 87.578 \\
\hline & $20000>$ & 6.816 & .615 & .000 & 912.511 & 273.327 & 3046.447 \\
\hline \multirow{4}{*}{ Wealth Index } & (Poor) & & & .891 & & & \\
\hline & Middle & .161 & 1.496 & .914 & 1.175 & .063 & 22.064 \\
\hline & Rich & .386 & 1.560 & .805 & 1.471 & .069 & 31.267 \\
\hline & Constant & 21.505 & 4955.103 & 3.997 & .000 & & \\
\hline
\end{tabular}

Note: $* \mathrm{P}<0.05, * *<0.01, * * *<0.001, \mathrm{CI}=$ confidence interval; parentheses indicate the reference categories

\section{Discussion and Conclusion}

The study aimed to find out overall scenario on the delivery process in Chittagong, Bangladesh. Findings in this study show that the high cesarean rate is observed in the age group 26-35 years (55\%). There were wide variations in cesarean delivery rate among rural $(28.8 \%)$ and urban $(71.2 \%)$ residence in Chittagong. As the education statues increases, the cesarean rate also increases. Cesarean section rate of private hospitals in Chittagong is $(81.1 \%)$ while in public hospitals the rate is only $7.9 \%$. Cost of C-section delivery is also five-fold higher than normal delivery. Most of the C-section deliveries occur from 2011 to 2018. Mothers' physical problems are the most common cause of high cesarean births. The rate of cesarean section delivery is low among the women who never have visited the doctors' chamber. Important reasons for C-section were mother's physical problem (43.1\%). The trend analysis 
shows that cesarean sections have increased continuously during the period from 2011 to 2017 . Studies have found that the current cesarean births rate of Chittagong region is 24.12 percent. The cesarean delivery rate has been increasing rapidly for the last seven years in Chittagong. Overall 65\% deliveries in Chittagong have a cesarean delivery, and only $35 \%$ were normal delivery. Therefore, it is alarming that $\mathrm{C}$-section rate in Chittagong region was much higher than the national average as well as global recommendations level $(<15 \%)$ by WHO. The results of bivariate analysis explored that among the twelve independent variables, nine independent variables have been found statistically significantly associated with the delivery process. Logistic regression analysis revealed that only two variables 'delivery place' and 'cost of last delivery' have a significant effect on the delivery status in Chittagong. These two important factors are directly responsible for increasing in C-section rate in Chittagong, Bangladesh.

\section{Recommendations}

Based on the findings of this research, the following are the recommendation for the policymakers to reduce high rate of cesarean sections in Chittagong:

(i) Findings of the study demonstrated that 'delivery place' (Public/Private hospital) is an important determinant of $\mathrm{C}$-section. Therefore, government should ensure strong supervision in all private hospitals in Chittagong as well as in the whole country to reduce unnecessary C-section;

(ii) Delivery facilities should be increased in the government hospitals across the whole country;

(iii) Cost of last delivery is another important significant factor for determining the delivery mode. Therefore, Consciousness should be created among the highly educated and high socioeconomic class in Chittagong;

(iv) The mass media campaign should be strengthened about the long-term effects of the cesarean operation;

(v) To reduce C-section delivery in Chittagong as well as in the whole country, maternal health status should be taken care of;

(vi) Finally, to perform a C-section delivery the moral and ethical standard of doctors and hospitals should be maintained.

Proper implementation of the above recommendations might help to reduce the high C-section rates in Chittagong, Bangladesh.

\section{Conflict of Interest and Declaration}

The authors declare that they have no competing interests and the submission is not considered elsewhere.

\section{Acknowledgments}

The authors devoted to all women in Chittagong region who have participated this study and giving their personal information.

\section{References}

Adam,, I. (2014). Epidemic/pandemic of Cesarean delivery: the scope of the problem. International journal of health sciences, 8(1). :V-VI.

Akintayo, A. A., Ade-Ojo, I. P., Olagbuji, B. N., Akin-Akintayo, O. O., Ogundare, O. R., \&Olofinbiyi, B. A. (2014). Cesarean section on maternal request: the viewpoint of expectant women. Archives of gynecology and obstetrics, 289(4), 781-785.

Aminu, M., Utz, B., Halim, A., \& Van Den Broek, N. (2014). Reasons for performing a cesarean section in public hospitals in rural Bangladesh. BMC pregnancy and childbirth, 14(1), 130.

Feng, X. L., Wang, Y., An, L., \&Ronsmans, C. (2014). Cesarean section in the People's Republic of China: current perspectives. International journal of women's health, 6, 59-74.

Gibbons, L., Belizan, J. M., Lauer, J. A., Betran, A. P., Merialdi, M., \&Althabe, F. (2012). Inequities in the use of cesarean section deliveries in the world. American journal of obstetrics and gynecology, 206(4), 331-e1.

Huda, F. A., Ahmed, A., Dasgupta, S. K., Jahan, M., Ferdous, J., Koblinsky, M., ...\& Chowdhury, M. E. (2012). Profile of maternal and foetal complications during labour and delivery among women giving birth in hospitals in Matlab and Chandpur, Bangladesh. Journal of health, population, and nutrition, 30(2), 131.

https://thefinancialexpress.com.bd/health/70pc-of-cesarean-births-in-bangladeshunnecessary-1502855632

https://www.thedailystar.net/starweekend/health/the-curious-case-the-c-selection-1432768

Islam, S.: Banglapedia: national encyclopedia of Bangladesh, vol. 3. Asiatic society of Bangladesh (2003)

Jisun, T. F., \&Kabir, M. R. (2014). A Comparative Study on the Preference for Delivery Process in Bangladesh. ABC Journal of Advanced Research, 3(1), 24-28.

Khan, R., Blum, L. S., Sultana, M., Bilkis, S., \&Koblinsky, M. (2012). An examination of women experiencing obstetric complications requiring emergency care: perceptions and sociocultural consequences of cesarean 
sections in Bangladesh. Journal of health, population, and nutrition, 30(2), 159.

Lowdon, G., \& Derrick, D. C. (2002). Cesarean Section Or Vaginal Birth? What Difference Does It Make?.AIMS JOURNAL, 14(1), 1-4.

Mossialos, E., Allin, S., Karras, K., \&Davaki, K. (2005). An investigation of Cesarean sections in three Greek hospitals: the impact of financial incentives and convenience. The European Journal of Public Health, 15(3), 288-295.

National Institute of Population Research, Training (Bangladesh), Mitra and Associates (Firm), \& Macro International. (2016). Bangladesh Demographic and Health Survey, 2014. NIPORT.

Neuman, M., Alcock, G., Azad, K., Kuddus, A., Osrin, D., More, N. S., ...\&Sen, A. (2014). Prevalence and determinants of cesarean section in private and public health facilities in underserved South Asian communities: cross-sectional analysis of data from Bangladesh, India and Nepal. BMJ open, 4(12), e005982.

Onwude, J. L., Rao, S., \&Selo-Ojeme, D. O. (2005). Large babies and unplanned Cesarean delivery. European Journal of Obstetrics \& Gynecology and Reproductive Biology, 118(1), 36-39.

Parrish, K. M., Holt, V. L., Easterling, T. R., Connell, F. A., \&Logerfo, J. P. (1994). Effect of changes in maternal age, parity, and birth weight distribution on primary cesarean delivery rates. Jama, 271(6), 443-447.

Rahman, M., Shariff, A. A., Saaid, R., \&Shafie, A. (2012). Age at marriage, maternal age and cesarean delivery of first birth in the northern region of Bangladesh: a study on curve estimation. Man in India, 92(1), 93-113.

Skalkidis, Y., Petridou, E., Papathoma, E., Revinthi, K., Tong, D., \&Trichopoulos, D. (1996). Are operative delivery procedures in Greece socially conditioned? International Journal for Quality in Health Care, 8(2), $159-165$

Strom, S. (2013). Rates, Trends and Determinants of Cesarean Section Deliveries in El Salvador: 1998 to 2008 (Doctoral dissertation).

WHO, U., \&Unicef. (2009). AMDD: Monitoring emergency obstetric care: a handbook. Geneva: WHO, 152(4), 430 